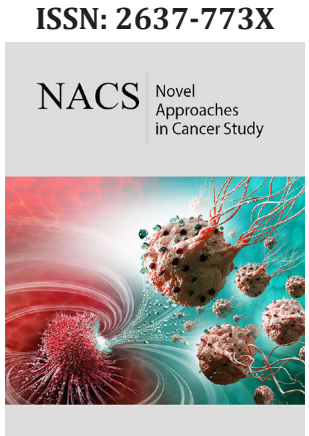

*Corresponding author: Madhumita Roy, Department of Environmental Carcinogenesis \& Toxicology, Chittaranjan National Cancer Institute, 37, S P Mukherjee Road, Kolkata, India, Email: mitacnci@yahoo.co.in

Submission: 監 March 13, 2020

Published: 想 May 04, 2020

Volume 4 - Issue 4

How to cite this article: Archismaan Ghosh, Madhumita Roy. Prevalence of Gallbladder Cancer in Arsenic Endemic Areas. Nov Appro in Can Study. 4(4). NACS.000593. 2020. DOI: 10.31031/NACS.2020.04.000593

Copyright@ Madhumita Roy. This article is distributed under the terms of the Creative Commons Attribution 4.0 International License, which permits unrestricted use and redistribution provided that the original author and source are credited.

\section{Prevalence of Gallbladder Cancer in Arsenic Endemic Areas}

\author{
Archismaan Ghosh and Madhumita Roy*
}

Department of Environmental Carcinogenesis \& Toxicology, Chittaranjan National Cancer Institute, 37, S P Mukherjee Road, Kolkata, India

\begin{abstract}
Association between exposure to high arsenic content and gallbladder cancer is scanty. Few reports suggest that the incidence of gallbladder cancer is high along the Indo-Gangetic belt. Inflammation, which is a causative factor for gallbladder carcinoma can be induced by arsenic. Prognosis of gallbladder cancer is poor. Therefore, it is worthwhile to find a correlation between arsenic exposure and its incidence to identify a population who are at high risk category.
\end{abstract}

Keywords: Arsenic; Gallbladder cancer; inflammation; Indo Gangetic belt

\section{Introduction}

Groundwater is one the most important source of drinking water in the world. Contamination of groundwater by arsenic is a major health issue which is escalating day by day. More and more areas are being reported with arsenic content much higher than the safe limit of $10 \mu \mathrm{g} / \mathrm{L}$ set by WHO [1]. Apart from a plethora of health hazards, chronic exposure to arsenic is known to cause cancer of the skin, lung, bladder, liver, kidney and prostrate [2]. Association between presence of arsenic and cancer of the gallbladder has not been reported as much. But, epidemiological evidence indicates a link between incidences of gallbladder cancer in arsenic endemic areas. World wide geographic distribution of arsenic contaminated areas share remarkable similarity with regions reporting high prevalence of gallbladder cancer, especially in Chile, India and Bangladesh [3]. In India, the Indo-Gangetic belt has the highest number of recorded cases of gallbladder cancer, maximum amongst them being reported from the Kamrup district in Assam [4]. This region of Eastern India also harbors areas with the highest groundwater arsenic contamination [5].

Gall bladder cancer is a rare malignancy but has very high mortality rate with less than 5 years of survivability [6,7]. Apart from known risk factors like age, sex, presence of gall stones, ethnic origin [8], and environment may be a key player in the etiology of gallbladder cancer. Environmental risk factors include water contamination by heavy metals like lead, cobalt, mercury, arsenic, chromium, and cadmium. Of these, exposure to elevated amount of cadmium, cobalt, lead, mercury is marked as causative factors for gallbladder carcinogenesis [9]. Prognosis of gallbladder cancer is poor and that may be attributed to its late diagnosis, when the disease has advanced and metastasis has already taken place [8].

Arsenic has been declared as a Group 1 carcinogen by the International Agency for Research on Cancer, based on the substantial evidence for their carcinogenicity in humans [2]. The Majority of the ingested arsenic undergoes biotransformation in the liver and the metabolites are excreted mainly in the urine, causing renal cancer [10]. These metabolites often are excreted into the bile [11,12]. Arsenic may be responsible for carcinogenesis of the biliary tract cancer, the most common of which being gallbladder cancer [13]. Statistical analysis investigating the ecological correlation between the arsenic concentrations and incidences of gall bladder cancer have shown positive trends both in Indian and Taiwanese populations [2]. 
Inflammation plays an important role in the development of gallbladder carcinoma. A Chronic inflammatory state in the gallbladder leads to the diffused calcification of the wall of gall bladder. This phenomenon ultimately leads to development of porcelain gallbladder, which imparts a very high risk in the development of gallbladder carcinoma [14]. Congenital diseases represented by abnormal pancreaticobiliary junctions, result in excess flow of pancreatic enzymes into the gall bladder. This may cause persistent inflammation, resulting in carcinogenesis of the gall bladder [15]. Persistent Inflammation due to bacterial infections like Salmonella typhi or Helicobacter bilis can also lead to an increased risk of gall stone formation and cancer progression [16]. Therefore it is observed that conditions of chronic inflammation which lead to DNA damage and tissue proliferation may serve to be a suitable microenvironment for development of gallbladder carcinoma. Similarly chronic exposure of arsenic is also known to promote the prolonged inflammation which in turn promotes the development of cancer $[17,18]$. The accumulation of the secondary metabolites of arsenic biotransformation in the bile by the liver may result in a chronic inflammatory condition thus promoting the chances of the development of gallbladder carcinoma. Arsenic methyl (III) transferase AS3MT, an enzyme, which is responsible for the methylation of trivalent arsenic species, plays the most important role in its biotransformation. Mutations in the gene AS3MT have been associated with an increase in the development of gallbladder carcinoma [19] and therefore screening of this gene may serve as a biomarker in the development of gall bladder carcinoma as well where the unmethylated arsenical pile up in the bile instead of the urine.

Another important enzyme, Glutathione S transferase $\mathrm{Mu}$ 1 (GSTM1) plays an important role in the methylation of arsenic [20], which has also been implicated in gall bladder cancer. People with null phenotype of GSTM1 were reported to have much higher susceptibility towards development of gall bladder carcinoma [21]. Individuals with null phenotype of GSTM1 due to incomplete methylation lead to accumulation of monomethylated arsenic products and may result in cancer. Not much data are available on gallbladder cancer to date. To fill up the lacunae in information, genome wide association studies (GWAS) may be of help. This will constitute single nucleotide polymorphism (SNP), as well as individual gene profiling. On the other hand the carcinogenic spectrum of arsenic is known. Lethal similarities in the geographic distribution of arsenic and its ability to cause prolonged inflammation may hint at its incognito role in causing gallbladder cancer. Biotransformation of arsenic results in systematic stress in individuals which could be a factor for its carcinogenicity in many cases. In gallbladder cancer these incompletely methylated arsenicals may play similar role. Therefore, we emphasize that arsenic can be one of the causes for gallbladder cancer but further investigation is required.

\section{Conflict of Interest}

The authors have no conflict of interest.

\section{References}

1. George CM, Sima L, Arias MH, Mihali J, Cabrera LZ, et al. (2014) Arsenic exposure in drinking water: An unrecognized health threat in Peru. Bulletin of the World Health Organization 92(8): 565-572.

2. (2012) IARC monographs on the evaluation of carcinogenic risks to humans, No. 100C. International Agency for Research on Cancer, Lyon, France.

3. Ganesan N, Bambino K, Boffetta P, Labgaa I (2020) Exploring the potential carcinogenic role of arsenic in gallbladder cancer. European Journal of Cancer Prevention 29(2):100-109.

4. Madhawi R, Pandey A, Raj S, Mandal M, Devi S, et al. (2018) Geographical pattern of carcinoma gallbladder in Bihar and its association with river Ganges and arsenic levels: Retrospective individual consecutive patient data from Regional Cancer Centre. South Asian J Cancer 7(3):167-170.

5. Chakraborti D, Singh SK, Rahman MM, Dutta RN, Mukherjee SC, et al. (2018) Groundwater arsenic contamination in the Ganga river basin: A future health danger. Int J Environ Res Public Health 15(2): 180-199.

6. Are C, Ahmad H, Ravipati A, Croo D, Clarey D, et al. (2017) Global epidemiological trends and variations in the burden of gallbladder cancer. J Surg Oncol 115(5): 580-590.

7. Randi G, Franceschi S, La Vecchia C (2006) Gallbladder cancer worldwide: Geographical distribution and risk factors. Int J Cancer 118(7): 15911602.

8. Mahdavifar N, Mohammadian M, Salehiniya H (2018) Gallbladder cancer in the world: Epidemiology, incidence, mortality and risk factors. World Cancer Research Journal 5(3): e1124.

9. Mondal B, Maulik D, Mandal M, Sarkar GN, Sengupta S, et al. (2017) Analysis of carcinogenic heavy metals in gallstones and its role in gallbladder carcinogenesis. J Gastrointest Canc 48(4): 361-368.

10. Chen CL, Chiou HY, Hsu LI, Hsueh YM, Wu MM, et al. (2010) Arsenic in drinking water and risk of urinary tract cancer: A follow-up study from northeastern Taiwan. Cancer Epidemiol Biomarkers Prev 19(1): 101110.

11. Argos M, Kalra T, Rathouz PJ, Chen Y, Pierce B, et al. (2010) Arsenic exposure from drinking water, and all-cause and chronic-disease mortalities in Bangladesh (HEALS): A prospective cohort study. Lancet 376(9737): 252-258.

12. Ponomarenko O, La Porte PF, Singh SP, Langan G, Fleming DEB, et al. (2017) Selenium-mediated arsenic excretion in mammals: A synchrotron-based study of whole-body distribution and tissue-specific chemistry. Metallomics 9(11): 1585-1595.

13. Schmidt MA, Marcano-Bonilla L, Roberts LR (2019) Gallbladder cancer: Epidemiology and genetic risk associations. Chin Clin Oncol 8(4): 31.

14. Berk RN, Armbuster TG, Saltzstein SL (1973) Carcinoma in the porcelain gallbladder. Radiology 106(1): 29-31.

15. Kimura W (2009) Congenital dilatation of the common bile duct and pancreaticobiliary maljunction: clinical implications. Langenbecks Arch Surg 394(2): 209-213.

16. Koshiol J, Wozniak A, Cook P, Adaniel C, Acevedo J, et al. (2016) Salmonella enterica serovar Typhi and gallbladder cancer: A case-control study and meta-analysis. Cancer Med 5(11): 3310-3235.

17. Druwe IL, Sollome JJ, Sanchez-Soria P, Hardwick RN, Camenisch TD, et al. (2012) Arsenite activates NFkB through induction of C-reactive protein. Toxicol Appl Pharmacol 261(3): 263-270.

18. Das N, Paul S, Chatterjee D, Banerjee N, Majumder NS, et al. (2012) Arsenic exposure through drinking water increases the risk of liver and cardiovascular diseases in the population of West Bengal, India. BMC Public Health 12: 639. 
19. Lin YC, Chen WJ, Huang CY, Shiue HS, Su CT, et al. (2018) Polymorphisms of arsenic ( +3 oxidation state) methyltransferase and arsenic methylation capacity affect the risk of bladder cancer. Toxicol Sci 164(1): 328-338.

20. Steinmaus C, Moore LE, Shipp M, Kalman D, Rey OA, et al. (2007) Genetic polymorphisms in MTHFR 677 and 1298, GSTM1 and T1, and metabolism of arsenic. J Toxicol Health Sci 70(2): 159-217.
21. Sakai K, Loza E, Roig GV, Nozaki R, Asai T, et al. (2016) CYP1A1, GSTM1, GSTT1 and TP53 polymorphisms and risk of gallbladder cancer in bolivians. Asian Pac J Cancer Prev 17(2): 781-784.

For possible submissions Click below: 